\title{
INVOLVEMENT OF MULTIPLE CELL LINEAGES IN ATHEROGENESIS
}

Julius A. Ogeng'o, Kevin W. Ongeti, Beda O. Olabu, Beryl S. Ominde

Correspondence to Prof. Julius Ogeng'o, Department of Human Anatomy, University of Nairobi Tel: 0720837592, Email: jogengo@uonbi.ac.ke

\begin{abstract}
Atherogenesis is a multicellular event. Early reports concentrated on the role of endotheliocytes, monocyte macrophages and smooth muscle cells. Recognition of the immuno-inflammatory nature of the process, however, expanded the scope of cellular involvement and more recent reviews emphasize the role of immune and inflammatory cells. In addition, recent studies reveal that other cells are also involved. Elucidation of all the types of cells involved is valuable to inform therapeutic interventions for this disease, but most accounts concentrate on cells which are the target of the study and may fail to include other cells. This review therefore aimed at consolidating information on the various cells involved in atherogenesis. Review of contemporary literature was done for cells in the vessel wall and in blood to check for their potential role in atherogenesis. It has been shown that atherogenesis involves all the cells present in the various coats of the vessel wall endotheliocytes, smooth muscle cells, fibroblasts, stem cells, pericytes, mast cells, dendritic cells, macrophages and immigrant cells usually found in blood, namely monocytes, neutrophils, lymphocytes, platelets and red blood cells. These cells promote atherogenesis by secreting several products which influence inflammation, migration, proliferation and secretory activity of each other in a manner that synergises their activities. Therapeutic interventions should target the various cell types.
\end{abstract}

Key Words: Cells, arterial wall, blood, atherogenesis.

\section{INTRODUCTION}

Knowledge of the cells involved in atherogenesis is valuable in understanding the pathobiology of and the therapeutic approaches in management of atherosclerosis. Previous models depicted atherosclerosis as an inert lipid handling disorder which merely involved endotheliocytes, smooth muscle cells and monocyte / macrophages. Recognition of inflammatory nature of this disease (Packard and Libby, 2008; Libby et al., 2009; Libby, 2012) increased the scope of cells involved. The classical view advanced was that the process involves three cellular components in circulation - monocytes, $\mathrm{T}$ lymphocytes and platelets; together with two cells of the arterial wall namely endothelial and smooth muscle cells. Further analysis expanded the repertoire of cells to include most known inflammatory and immune cells - monocytes, macrophages, dendritic cells, neutrophils, various categories of lymphocytes and mast cells (Hanson and Libby, 2006; Spagnoli et al., 2007; Galkina and Ley,
2007; Libby et al., 2011; Libby, 2012). There are several recent excellent reviews on cellular and molecular mechanisms which underly this immunoinflammatory process of atherosclerosis (Gomez - Guerrero et al., 2012; Wong et al., 2012; Ilhan and Kalkanli, 2015). Indeed, experimental studies on these cellular mechanisms continue to reveal potential for their successful application in development of drugs to mitigate initiation, progression and complications of atherosclerosis (Tabas et al., 2015; Ivanova and Orekhov, 2016). Most of these reviews, however, focus on specific cells which constitute the therapeutic targets under study and often do not cover all cells. As atherosclerosis continues to be a major health challenge worldwide, there is need for accounts that include as many cells as possible in this process. This review, therefore, aimed at consolidating available knowledge on the types of cells involved in atherogenesis.

Submitted $30^{\text {th }}$ September 2016, revised on $7^{\text {th }}$ November 2016. Published online $12^{\text {th }}$ July 2017 . To cite Ogeng'o J, Ongeti K, Olabu B, Ominde B. 2017. Involvement of multiple cell lineages in atherogenesis. Anatomy Journal of Africa. 6 (2): 924 $-933$. 
Anatomy Journal of Africa. 2017. Vol 6 (1): 924 -933

\section{LITERATURE REVIEW}

Articles were retrieved from Google search using the following combinations of key words - cells, atherosclerosis; cells, atherogenesis; cellular involvement, atherogenesis; inflammation, atherosclerosis. Original articles on human, animal, experimental studies and several classical review papers were reviewed. Special emphasis was put on articles published between 2006 and 2016. Only those papers in which the role of the cells was explicit were included. Many papers were excluded for lack of clarity, being too old, and not being explicit.

\section{FINDINGS}

A total of 13 main cell types were involved in the process of atherogenesis. The cells comprised those which are usual constituents of the vessel wall and formed elements of normal blood. These are highlighted below.

a. The endothelial cells: Previously considered to be an inert, semi - permeable barrier between blood and the vascular wall, the endothelium is now known to be critical in maintenance of vascular homeostasis. When activated/injured, it exhibits pro inflammatory, oxidant, proliferative, procoagulative and proadhesive features which trigger and promote atherosclerosis (Chhabra, 2009; Mudau et al., 2012; Tabas et al., 2015). The role of the endothelium in atherosclerosis is through production of endothelin and angiotensin II which promote proliferation of smooth muscle cells and thereby contribute to the formation of plaque (Mehta and Grendling, 2007; Suen et al., 2011; Kohan et al., 2011). Damage to the endothelium initiates endothelial permeability, platelet aggregation, leukocyte adhesion and generation of cytokines which promote or exacerbate atherosclerosis. Activation of endothelial cells at atherosclerotic lesion prone sites causes upregulation of cell adhesion molecules and cytokines which mediate recruitment of circulating monocytes whose accumulation leads to chronic inflammation, development and progression of atherosclerosis (Mestas and Ley, 2008; Ley et al., 2011; Ghattas et al., 2013; Vitiello et al., 2014). b. Vascular smooth muscle cells: Vascular smooth muscle cells (VSMC) migrate from the media to intima, where they proliferate and form a neointima with increased extracellular matrix (ECM) formation leading to development of an organized atherosclerotic plaque. These VSMC changes are thought to constitute a late event in atherosclerotic process (Rudijanto, 2007). VSMC may take on a "proinflammatory" phenotype whereby they secrete cytokines and express cell adhesion molecules like $1 \mathrm{~L}-8 ; 1 \mathrm{~L}-6$ and VCAM - 1 which functionally regulate monocyte and macrophage adhesion and other processes during atherosclerosis (Orr et al., 2010; Christiakov et al., 2015). Further, VSMC actively mediate inflammation through their regulation of cytokine secretion and membrane receptors (Lim and Park, 2014). Genetic studies have revealed that VSMC switching results in less differentiated forms that lack VSMC markers including macrophage - like cells which promotes atherosclerosis (Bennett et al., 2016)

c. Monocytes: Monocytes are attracted to and adhere to the dysfunctional endothelium, migrate to the subendothelial zone (SEZ) where they transform into inflamatory macrophages and dendritic cells. These three cells play critical roles in initiation and progression of atherosclerosis (Ley et al., 2011). Two types of monocytes exist: the proinflammatory and the less inflammatory one. The inflammatory one expresses high level of toll-like receptors (TLR) and elaborate cytokines such as tumor necrotic factor (TNF) and interleukin (IL)-1. They also produce proinflammatory cytokines, reactive oxygen species, macrophage mediators including matrix metalloproteinases, peroxides, chemokines, adhesion molecules and growth factors (Libby et al., 2008; Pamukcu et al., 2010). The less inflammatory ones express higher levels of transforming growth factors beta (TGF- $\beta$ ), scavengers receptor (CD 36), scavenger receptor $A$ (SR-A) and angiogenesis mediators including vascular endothelial growth factor (VEGF) [Libby et al., 2009]. Monocytes therefore play a major role in initiation, propagation and progression of atherosclerosis 
from a stable to unstable state (Ghattas et al., 2013).

d. Macrophages: Macrophages play diverse roles in atherogenesis. They modulate lipid metabolism and secrete cytokines, reactive oxygen and nitrogen species that drive atherogenesis. They also produce proteases and tissue factors that contribute to plaque rupture and thrombosis (Wilson, 2010; Stoger et al., 2010). They function as scavenger cells and immune mediators (Gui et al., 2012). Cholesterol loaded macrophages are a characteristic feature of plaques and major players in all stages of plaque development. They participate in a mal adaptive, unrelenting inflammation leading to further cellular infiltration, lipid and ECM accumulation in the SEZ (Moore and Tabas, 2011). Upon internalization of oxidized lowdensity lipoprotein (Ox - LDL), they transform into foam cells whose accumulation in the arterial wall initiates formation of fatty streaks that subsequently develop into advanced plaques (Michael et al., 2012). The chemokines promote migration of monocyte into the tunica intima. Monocyte chemoattractant protein-1 (MCP-I) attracts monocytes. Macrophage also express cyclooxygenose - 2, a key enzyme in inflammation which promotes atherosclerotic lesion formation (Tabas et al., 2015). Two types of macrophages exist in atherosclerotic plaquesinflammatory (M1) and anti-inflammatory (M2). The $\mathrm{M} 1$ predominates in disease progression and M2 in regression (Peled and Fisher, 2014). A distinct non - foam macrophage termed $M(\mathrm{Hb})$ promotes plaque neoangiogenesis and microvessel via a non - lipid driven mechanism - the a HIF - Ia/VEGF - A- dependent pathway (Finn et al., 2016). By virtue of their versatility and plasticity, macrophages are able to promote a series of pathogenic functions ranging from release of cytokines, enzymes, reactive oxygen species, presentation of antigens and secretion of tissue remodeling factors (Shirai et al., 2015). e. Platelets: Platelets are involved in the initiation, development and total extent of atherosclerotic lesions (Lindemann et al., 2007) by binding to leucoytes and endothelial cells, and initiating monocyte transformation into macrophages. They also facilitate the recruitment of inflammatory cells towards the lesion sites and release various inflammatory mediators. The molecules present on the platelet surface and /or stored in platelet granules such $P$ - Selectin, chemokines and inflammatory cytokines; PDGF Platelet factor 4 (PF - 4) RANTES: IL -8 and MCP -1 contribute to the cross - talk of platelets with the inflammatory cells in the development and progression of atherosclerosis (Davi and Patrono, 2007). This cross - talk among platelets, endothelial cells and leucocytes establishes a localized inflammatory response that accelerates atherosclerosis (Kaplan and Jackson, 2011). They also enforce leukocyte activation, adhesion and transmigration (Lievens and Hundelshausen, 2011). Further, they participate in atherogenesis by releasing chemokines, surface association with Ox - LDL, direct cell cell interaction, release of microparticles, pro inflammatory IL - IB, and recruitment of leucocytes (Nording et al., 2015).

f. Lymphocytes: Lymphocytes play an important role in early atherogenesis. Circulating T-cells migrate into the atherosclerotic lesions in response to chemo attractants which bind to the cell specific receptors. Within the plaque, various antigens such as MLp induce further T-cell proliferation (Packard et al., 2009). Further, the $\mathrm{T}$ cells respond to inflammatory signals by orchestrating the production of IFN $-\mathrm{Y}$ and TNF $-\beta$ which stimulate monocyte/macrophages, dendtric cells (DC), endothelium and SMC to perpetuate the inflammatory response in atherosclerosis (Libby, 2012; Profumo et al., 2012). B cells direct the immune response during the development of the atherosclerotic plaque (Galkina and Ley, 2009). Both T and B lymphocytes, as components of adaptive immune system, modulate different immunopathogenic mechanisms in atherosclerosis (Ketelhuth and Hanson, 2014). There are multiple potential pathways by which B cells can promote atherosclerosis, for example by producing cytokines and directly regulating $T$ cell responses (Sage and Mallat, 2014). Other mechanisms by which lymphocytes influence 
atherogenesis include their cross-talk with myeloid cells (Hedrick, 2015)

g. Dendritic cells: Mature DCs accumulate during atheroprogression, cluster with $\mathrm{T}$ cells (Galkina et al., 2006; Weber et al., 2008; 2011) and present antigens such as ox - LDL to naive $T$ cells (Packard et al., 2008). They express major histocompatibility complex I and II, human leucoyte antigen - DR, CDla, intercellular adhesion molecule 1 , vascular cell adhesion molecule - 1 and co - stimulatory molecule on their surfaces which activate naïve $T$ cells. Activation of $T$ cells leads to release of cytokines which are important in disease progression (Sharma, 2006; Ranjit and Dazhu, 2006). They contribute to early foam cell formation, regulate lipid uptake and metabolism (Alberts - Grill et al., 2013; Zernecke, 2015) and participate in all stages of atherosclerosis from fatty streaks to mature lesions (Koltsova and Ley, 2011; Bobryshev et al., 2013) mainly by modulating adaptive immune responses (Alberts - Grill et al., 2013; Zernecke, 2015).

h. Neutrophils: Neutrophils are induced by $O x$ - LDL to transmigrate into SEZ and release reactive oxygen species and granule proteins such as myeloperoxidase, azurocidin, proteinase - 3, cathepsin G, a-defensins, neutrophil elastase, proteinase -3 which in turn trigger monocyte recruitment through the various "findme and eat me" signals They trigger a chronic inflammatory response that sustains atherogenesis (Soehnlein and Lindbom, 2010; Weber and Noels, 2011). These aggravate endothelial dysfunction, lure monocytes into the lesion, activate macrophages and promote foam cell formation and contribute to plaque destabilization, promote endothelial erosion and contribute to weakening of fibrous cap (Soehnlein, 2012; Doring et al., 2015; Federico et al., 2015). They promote plaque vulnerability by releasing gelatinases, collogenases, elastase and myeloperoxidase (Carbone et al., 2015). Proteolysis of the ECM mediated by neutrophil proteases promote atheroprogression and thrombus growth and plaque destabilization (Massberg et al., 2010; Hartwig et al., 2015; Pende et al., 2016). i. Mast cells: Mast cells are pro-inflammatory effector cells present in the human arterial intima and in evolving atherosclerotic lesions (Kovanen, 2009; Galkina and Ley, 2009). They are actively involved in the initiation, progression and destabilization of atherosclerosis by inducing atherogenic lipid profile and vascular inflammation (Bot et al., 2007; Sun et al., 2007; Tang et al., 2009; Heikkila et al., 2010; Smith et al., 2012). They produce interleukin (IL) - 6; and interferon (IFN) - $\mathrm{Y}$ which promote atherogenesis by augmenting the expression of matrix - degrading proteins and proinflammatory cytokines. Other mast cell specific proteases such as chymase, tryptase, cathepsin, heparin and growth factors, histamine and chemokines play different roles in atherogenesis including matrix degradation, apoptosis and enhanced recruitment of inflammatory cells (Sun et al., 2007; Bot and Biesen 2011; Spinas et al., 2014; Wezel et al., 2015; Bot et al., 2015) indirectly influencing activity of other cells of immune system, modulating proliferation and apoptosis of endothelial and VSMC (Czyzewska - Buczynska and Witkiewicz, 2011)

Some of the factors such as f-GF and histamine activate SMC surface receptors and accelerate their migration and proliferation. The elevation of the cytokines/chemokines may contribute to leulocyte adhesion and migration, foam cell formation and SMC apoptosis (Pfeniger et al., 2013). In addition, mast cells participate in lipid retention and vascular cell remodeling and are mediators of innate and adaptive immunity during atherosclerosis (Spinas et al., 2014; Wezel et al., 2015).

j. Fibroblasts: Fibroblasts, when activated in response to injury, stretch, cytokines and hormones, release reactive oxygen species which stimulate cellular differentiation, migration, proliferation and collagen synthesis. Further, fibroblast $\mathrm{NAD}(\mathrm{P}) \mathrm{H}$ oxidase plays a direct role in neointimal hyperplasia as well as a paracrine role in vascular smooth muscle hypertrophy (Haurrani and Pagano, 2007). Fibroblasts also express several proinflammatory cytokines such as chemoattractant protein -1 
(MCP - 1); $1 \mathrm{~L}-6$, protein and mRNA (Xu et al., 2007). During early stages of vascular insult, fibroblasts proliferate and migrate to the media and intima and effect inflammatory response by increasing production of ROS and release of various proinflammatory cytokines, growth factors, matrix metalloproteinases which synergistically initiate neointima formation followed by subsequent atherosclerosis (Liu and Kong, 2010). The MCP -1 recruits monocytes which further activate fibroblast proliferation, adventitial thickening and additional cytokine production. The fibroblast monocyte amplification loop mediates adventitial inflammation in atherosclerosis (Tieu et al., 2011).

k. Vascular stem cells: These are undifferentiated oligopotent progenitor cells from blood, bone marrow or tunica adventitia which are capable of giving rise to mature functional cells in the vascular wall including endothelial and smooth muscle cells (Geng et al., 2006). They contribute to atherosclerosis by migrating into the intima and differentiating into "abnormal" proliferative smooth muscle cells (Geng et al., 2006; Margariti et al., 2006; Tang et al., 2012; Bobryshev et al., 2012). When exposed to risk factors, multipotent vascular stem cells become proliferative and differentiate into VSMC that contribute to neointimal hyperplasia and hence atherogenesis (Tang et al., 2012). The vascular resident stem cells are also capable of differentiating into myofibroblasts that subsequently migrate to intima and contribute to neointimal hyperplasisa, vascular smooth muscle cells and endothelial cells that contribute to atherosclerosis (Kawabe and Hasebe, 2014).

I. Pericytes: Pericytes, also called Rouget or perivascular cells, constitute a pool of branched or stellate cells located around and sharing a basement membrane with endothelial cells in the heart, large and small vessels. They are located in the subendothelial zone and in the tunica adventitia (Diaz - Flores, 2009; Volz et al., 2015). They are usually involved in maintenance of vascular contractility, permeability, control of vascular pressure, angiogenesis, immune defence, production of extracellular matrix and keeping stability of the vessels (Diaz - Flores, 2009; Armulik et al., 2011). They are pluripotent and can give rise to various cells including macrophages and myofibroblasts (Dulmovits and Herman, 2012).

These cells have been implicated in all stages of atherosclerosis from initiation and progression to complication (Orekhov et al., 2014; Orekhov et al., 2015) by various mechanisms: For example they may produce signaling molecules which attract and recruit inflammatory cells or be involved in lipid accumulation and formation of foam cells (Ivanova et al., 2015); promote growth and vascularization of the atherosclerotic plaque; participate in local inflammatory process and thrombosis (Ivanova and Orekhov, 2016). Some studies have even provided evidence that it is the pericyte - like cells rather than SMC and other cells which are the key cellular element promoting the formation of atherosclerotic lesions (Orekhov and Bobryshev, 2015).

m. Red Blood Cells: Red blood cell (RBC) microvesicles enhance activation of vascular endothelium leading to vascular inflammation and atherogenesis (Blum, 2009). The cell membrane and haemoglobin of RBCs are both atherogenic. The cholesterol component of the membrane contributes to lipid deposition and lipid core expansion upon intraplaque hemorrhage. Cell - free haemoglobin is prone to oxidation and the oxidation products possess proxidant and proinflammatory activities (Jeney et al., 2014). Cross talk between RBC and immune cells contributes to progression of atherosclerosis. In particular, oxidized, senescent or stored RBC due to surface antigen modification and release of pro- oxidant and pro inflammatory molecules impair innate and adaptive immune response. Further, stored RBC accompanied by shredding of extracellular vesicles stimulate blood mononuclear cells and macrophages to release proinflammatory cytokines (Buttari et al., 2015).

In conclusion atherogenesis involves all the cells in the vessel wall and in blood. These cells interact synergistically with each other through 
Anatomy Journal of Africa. 2017. Vol 6 (1): 924 -933

various chemical signals which influence proliferation migration and secretory activity. Interventional research should target multiple cell lineages.

\section{ACKNOWLEDGEMENT}

We are grateful to Mrs. Antonina Odock - Opiko for meticulously typing and editing the manuscript.

\section{REFERENCES}

1. Alberts - Grill N, Denning TL, Rezvan A, et al. 2013. The role of vascular dendritic cell network in atherosclerosis. Am J Physiol Cell Physiol, 305: C1 - 21.

2. Armulik A, Genove G, Betsholtz C. 2011. Pericytes: developmental, physiological and pathological perspectives, problems, and promises. Dev Cell, 21: $193-215$.

3. Bennett MR, Sinha S, Owens GK. 2016. Vascular smooth muscle cells in Atherosclerosis. Circ Res, 118: $692-702$.

4. Blum A. 2009. The possible role of red blood cell microvesides in atherosclerosis. Eur J Int Med, 20: $101-105$.

5. Bobryshev YV, Karagodin VP, Orekhov AN. 2013. Dendritic cells and their role in Immune reactions of atherosclerosis. Cell Tissue Biol, 7: $113-125$.

6. Bobryshev YV, Orekhov AN, Soberun IA, et al 2012. Smooth muscle cells in atherosclerosis: possible role of stem cells and osteoblasts. J Cell Sci Ther, 3: 8.

7. Bot I, Biessen EA. 2011. Mast cells in atherosclerosis. Thromb Haemost, 106: $820-826$.

8. Bot I, De jager SC, Zernecke A, et al. 2007. Perivascular mast cells promote atherogenesis and induce plaque destabilization in apolipoprotein E - deficient mice. Circulation, 115: 2516 - 2525.

9. Bot I, Shi G - P, Kovanen PT. 2015. Mast cells as effectors in atherosclerosis. Arterioscler Thromb Vasc Biol, 35: 265 - 271.

10. Buttari B, Profumo E, Rigano R. 2015. Cross-talk between red blood cells and the immune system and its impact on atherosclerosis. Biomed Res Int, ID 616834. http://dx.doi.org/10.1155/2015/616834.

11. Carbone F, Mach F, Montecucco F. 2015. Update on the role of neutrophils in atherosclerotic plaque vulnerability. Curr Drug Targets; 16: 321 - 333.

12. Chhabra N. 2009. Endothelial dysfunction - A predictor of atherosclerosis. Internet J Med Update; 4: $33-41$.

13. Christiakov DA, Orekhov AN, Bobryshev YV. 2015. Vascular smooth muscle cell in atherosclerosis. Acta Physiol, 214: 33 - 50.

14. Czyzewska - Buczynska A, Witkiewicz W. 2011. Role of mast cells in the pathogenesis of atherosclerosis. Przegl Lek; 68: $171-174$.

15. Davi G, Patrono C. 2007. Platelet activation and atherothrombosis. M Eng J Med, 357: 2872 2494.

16. Diaz - Flores L, Gutierrez R, Madrid JF, et al. 2009. Pericytes, Morphofunction, interactions and pathology in a quiescent and activated mesenchymal cell niche. Histol Histopathol, 24: 909 - 969. doi:10:3109/0891634.2015.1027815.

17. Doring Y, Drechster M, Soehnlein O, et al. 2015. Neutrophils in atherosclerosis: from mice to man. Arterioscler ThrombVasc Biol, 2015; 35: 288 - 295.

18. Dulmovits BM, Herman IM. 2012. Microvascular remodeling and wound healing : a role for pericytes. Int J Cell Biol, 44: $1800-1812$.

19. Federico C, Francois M, Fabrizo M. 2015. Update on the role of neutrophils in atherosclerotic plaque vulnerability. Current Drug Targets, 16: $321-333$. 
Anatomy Journal of Africa. 2017. Vol 6 (1): 924 -933

20. Finn AV, Akahori $H$, Guo L, et al. 2016. Alternative macrophages promote intraplaque angiogenesis and vascular permeability in human atherosclerosis. Vascular Medicine; 67: 2241 2241.

21. Galkina E, Ley K. 2007. Leucocyte influx in atherosclerosis. Curr Drug Targets, 8: $1239-1248$.

22. Galkina E, Ley K. 2009. Immune and inflammatory mechanisms of atherosclerosis. Ann Rev Immunol, 27: 165 - 197.

23. Geng $Y-$ J, Yang $Y-$ J, Casscells SW, et al. 2006. Vascular stem cells: a new concept in the pathogenesis of atherosclerosis and intervention for coronary heart disease. Future Cardiology, 2: $585-592$.

24. Ghattas A, Griffiths HR, Devitt A, et al. 2013. Monocytes in coronary artery disease and atherosclerosis: where are we now? J Am Coll Cardiol, 62: 1541 - 1551.

25. Gomez - Guerrero C, Mallavia B, Egido J. 2012. Targetting inflammation in cardiovascular diseases. Still a neglected field? Cardiovasc Ther, 30: e 189 - 197.

26. Gui T, Shimokado A, Sun Y, et al. 2012. Diverse roles of macrophages in atherosclerosis: From inflammatory biology to biomarker discovery. Mediators Infl, Article ID 693083.

27. Hansson GK, Libby P. 2006. The immune response in atherosclerosis: a double - edged sword. Nature Reviews, 6: 508 - 519.

28. Hartwig H, Silvestre RC, Daemen M, et al. 2015. Neutrophils in atherosclerosis. A brief overview. Hemostaseologie; 35: $121-127$.

29. Haurani MJ, Pagano PJ. 2007. Adventitial fibroblast reactive oxygen species as autocrine and paracrine mediators of remodeling: bellwether for vascular disease? Cardiovasc Res, 75: 679 689.

30. Hedrick CC. 2015. Lymphochytes in atherosclerosis. Arterioscler Thromb Vasc Biol, 35: $253-257$.

31. Heikkila HM, Trosein J, Metso J, et al. 2010. Mast cells promote atherosclerosis by inducing both atherogenic lipid profile and vascular inflammation. J Cell Biochem, 109: 615 - 623.

32. Ilhan F, Kalkanli ST. 2015. Atherosclerosis and the role of immune cells. World J Clin Cases, 3: $345-352$.

33. Ivanova EA, Bobryshev YV, Orekhov AN. 2015. Intimal pericytes as the second line of immune defence in atherosclerosis. World J Cardiol, 7: 583 - 593.

34. Ivanova EA, Orekhov AN. 2016. Cellular model of atherogenesis based on pluripotent vascular wall pericytes. Stem Cells International, Article ID 7321404.

35. Jeney V, Balla G, Balla J. 2014. Red blood cell, hemoglobin and haeme in the progression of atherosclerosis. Front Physiol, 5: 379.

36. Kaplan ZS, Jackson SP. 2011. The role of platelets in atherothrombosis. ASH Education Book, 56 $-61$.

37. Kawabe J, Hasebe N. 2014. Role of the vasa vasorum and vascular resident stem cells in atherosclerosis. Biomed Res Int; Article ID 701571. http://dx.doi.org/10.1155/2014/701571.

38. Ketelhuth DFJ, Hanson GK. 2014. Lymphocytes in atherosclerosis. Encyclopedia of Med Immunol, $686-691$.

39. Kohan DE, Rossi NF, Inscho EW, et al. 2011. Regulation of blood pressure and salt homeostasis by endothelin. Physiol Rev, 91: $1-77$.

40. Koltsova EK, Ley K. 2011. How dendritic cells shape atherosclerosis. Trends Immunol, 32: 540 547.

41. Kovanen PT. 2009. Mast cells in atherogenesis: actions and reactions. Curr Atheroscler Rep, 11: $214-219$.

42. Ley K, Miller YI, Hedrick CC. 2011. Monocytes and macrophages dynamics during atherogenesis. Arterioscler Thromb Vasc Biol, 31: 1506 - 1516. 
43. Libby $P$, Nahrendorf M, Pittet MJ, et al. 2008. Diversity of denizens of atherosclerotic plaque. Not all monocytes are created equal. Circulation, 2008; 117: 3168 - 3170.

44. Libby P, Ridker PM, Hansson GK. 2009. Inflamation in atherosclerosis. From physiology to practice. J Am Coll Cardiol, 54: 2129 - 2138.

45. Libby P, Ridker PM, Hansson GK. 2011. Progress and challenges in translating the biology of atherosclerosis. Nature, 473: 317 - 325.

46. Libby P. 2012. Inflammation in atherosclerosis. Arterioscler Thromb Vasc Biol, 32: 2045 - 2051.

47. Lievens D, Von Hundelshausen P. 2011. Platelets in atherosclerosis. Thromb Haemost, 106: 827 $-838$.

48. Lim S, Park S. 2014. Role of vascular smooth muscle cell in inflammation of atherosclerosis. $B M B$ Rep, 47: $1-7$.

49. Lindemann S, Kramer B, Seizer $P$, et al. 2007. Platelets, inflammation and atherosclerosis. $J$ Thromb Haemost, 5: 203 - 211.

50. Liu ZY, Kong W. 2010. The role of adventitia in atherosclerosis. Sheng Li Ke Xue Jin Zhan, 41: $177-182$.

51. Margariti A, Zeng L, Xu Q. 2006. Stem cells, vascular smooth muscle cells and atherosclerosis. Histol Histopathol, 21: 979 - 985.

52. Massberg S, Grahl L, von Bruehl ML, et al. 2010. Reciprocal coupling of coagulation and innate immunity via neutrophil serine proteases. Nat Med, 16: $887-896$.

53. Mehta PK, Grendling KK. 2007. Angiotensin II cell signaling physiological and pathological effects in the cardiovascular system. Am J physiol, 292: C 82 - C 97.

54. Mestas J, Ley K. 2008. Monocyte endothelial cell interactions in the development of atherosclerosis. Trends in Cardiovasc Med, 18: 228 - 232.

55. Michael DR, Ashlin TG, Buckley ML, et al. 2012. Macrophages, lipid metabolism and gene expression in atherogenesis: a therapeutic target of the future? Clin Lipidol; 7: $37-48$.

56. Moore KJ, Tabas I . 2011. The cellular biology of macrophages in atherosclerosis. Cell; 145: 341 $-355$.

57. Mudau M, Genis A, Lochner A, et al. 2012. Endothelial dysfunction: the early predictor of atherosclerosis. Cardiovasc J Afr, 23: 222 - 231.

58. Nording HM, Seizer P, Langer HF. 2015. Platelets in inflammation and atherogenesis. Front Immunol; 6: 98.

59. Orekhov AN, Andreva ER, Inavova FA et al. 2015. Role of pericytes and modified lipoprotein in human atherogenesis. In coronary artery disease: Research and Practice. ISBN: $978-1-922227$ - 98 - 0. Iconcept Press.

60. Orekhov AN, Bobryshev YV, Christiakov DA. 2014. The complexity of cell composition of the intima of large arteries: focus on pericyte-like cells. Cardiovasc Res, 168: 438 - 451.

61. Orekhov AN, Bobryshev YV. 2015. Cell composition of the subendothelial aortic intima and the role of alpha smooth muscle actin expressing pericyte - like cells and smooth muscle cells in the development of atherosclerosis. Muscle cell and tissue, 29: $203-231$.

62. Orr AW, Hastings NE, Blackman BR, et al. 2010. Complex regulation and function of the inflammatory smooth muscle phenotype in atherosclerosis. J Vasc Res; 47: 168 - 180.

63. Packard RR, Lichtman AH, Libby P. 2009. Innate and adaptive immunity in atherosclerosis. Semin Immunopathol, 31: 5 - 22.

64. Packard RR, Maganto - Garcia E, Gotsman I, et al. 2008. CD11C (+). Dendritic cells maintain antigen processing, presentation capabilities, and $\mathrm{CD} 4(+) \mathrm{T}$ - cell priming efficacy under hypercholesterolemic conditions associated with atherosclerosis. Circ Res; 103: 965 - 973.

65. Pamukcu B, Lip GY, Devitt A, et al. 2010. The role of monocytes in atherosclerotic coronary artery disease. Ann Med; 42: 394 - 403. 
Anatomy Journal of Africa. 2017. Vol 6 (1): 924 -933

66. Peled M, Fisher EA, 2014. Dynamic aspects of macrophages polarization during atherosclerosis progression and regression. Front Immunol; 12/http://dx.doi.org/ 10.3389/fimmu.2004.00579.

67. Pende A, Artom N, Bertelotto M, et al. 2016. Role of neutrophils in atherogenesis: an update. Eur J Clin Invest; 46: $252-263$.

68. Pfenniger A, Chanson M, Kivak BR. 2013. Connexins in atheroscleroiss. Bio Chin Biophys Acta, 1828: 157 - 166.

69. Profumo E, Buttari B, Saso L, et al. 2012. T Lymphocyte autoreactivity in inflammatory mechanisms regulating atherosclerosis. The Sci World J, Article ID 157534.

70. Ranjit S, Dazhu L. 2006. Potential role of dendritic cells for progression of atherosclerotic lesions. Postgrad Med J, 82: 573 - 575.

71. Rudijanto A. 2007. The role of vascular smooth muscle cells on the pathogenesis of atherosclerosis. Acta Med Indones, 39: 86 - 93.

72. Sage AP, Mallat Z. 2014. Multiple potential roles for B cells in atherosclerosis. Annals of Medicine; 46: 5. Doi:10.3109/07853890.2014.900272.

73. Sharma R. 2006. Role of dendritic cells in atherosclerosis. Asian Cardiovasc Thorac Annals, 14: $166-169$.

74. Shirai T, Hilhorst M, Harrison DG, et al. 2015. Macrophages in vascular inflammation - From atherosclerosis to vasculitis. Autoimmunity; 48: $139-151$.

75. Smith DD, Tan X, Raveendran W. 2012. Mast cell deficiency attenuates progression of atherosclerosis and hepatic stenosis in apolipoprotein E - null mice. Am J Physiol Heart Pysiol, 302: $\mathrm{H} 2612-\mathrm{H} 2621$.

76. Soehnlein O, Lindbom L. 2010. Phagocyte partnership during the onset and resolution of inflammation. Nat Rev Immunol; 10: 427 - 439.

77. Soehnlein O. 2012. Multiple roles for neutrophils in atherosclerosis. Circ Res; 110: 875 - 888.

78. Spagnoli LG, Bonanno E, Sangiorgi G, et al. 2007. Role of inflammation in atherosclerosis. $\mathrm{J} \mathrm{NuCl}$ Med, 48: $1800-1815$.

79. Spinas E, Kritas SK, Saggini A, et al. 2014. Role of mast cells in atherosclerosis: A classical inflammatory disease. Int J Immunopath Pharmacol, 27: 517 - 521.

80. Stoger JL, Goosens P, de Winther MPJ. 2010. Macrophage heterogeneity: Relevance and functional implications in atherosclerosis. Curr Vasc Pharmacol, 8: $233-248$.

81. Suen RS, Rampersad SN, Stewart DJ, et al. 2011. Differential roles of endothelin -1 in Angiostensin - II induced atherosclerosis and aortic aneurysms in apolipoprotein $\mathrm{E}$ - null mice. Am J Pathol, 179; 1549 - 1559.

82. Sun J, Sukhova GK, Wolters PJ, et al. 2007. Mast cells promote atherosclerosis by releasing proinflammatory cytokines. Nature Medicine, 13: 719 - 724.

83. Tabas I, Garcia - Cardena G, Owens JK. 2015. Recent insights into the cellular biology of atherosclerosis. J Cell Biol, 209: $13-22$.

84. Tang Y, Yang Y, Wang S, et al. 2009. Mast cell degranulator compound 48 - 80 promotes atherosclerotic plaque in apolipoprotein $\mathrm{E}$ knockout mice with perivascular common carotid collar placement. Clin Med J, 122: 319 - 325.

85. Tang Z, Wang A, Yuan F, et al. 2012. Differentiation of multipotent vascular stem cells contributes to vascular diseases. Nat Commun, 3: 875.

86. Tieu BC, Ju X, Lee C, et al. 2011. Aortic adventitial fibroblasts participate in angiotensin - induced vascular wall inflammation and remodeling. J Vasc Res, 48: $261-272$.

87. Vitello L, Spoletini I, Gorini S, et al. 2014. Microvascular inflammation in atherosclerosis. IJC Metabolic and Endocrine; 3: 1 - 7.

88. Volz KS, Jacobs AH, Chen HI, et al. 2015. Pericytes are progenitors for coronary artery smooth muscle. Elife; 19: 4. 
89. Weber C, Noels H. 2011. Atherosclerosis: current pathogenesis and therapeutic options. Nat Med, 17: $1410-1422$.

90. Wezel A, Quax PH, Kuiper J, et al. 2015. The role of mast cells in atherosclerosis. Hamostaseologie; 35: $113-120$.

91. Wilson HM. 2010. Macrophages heterogeneity in atherosclerosis - implications for therapy. J Cell Mol Med, 14: 2055 - 2065.

92. Wong BW, Meredith A, Lin D, et al. 2007. The biological role of inflammation in atherosclerosis. Can J Cardiol, 28: 631 - 641.

93. $\mathrm{Xu} \mathrm{F}$, Li L, Chen R, et al. 2007. Adventitial fibroblasts are activated in early stages of atherosclerosis in apolipoprotein E knockout mouse. Biochem Biophys Res Comm, 325: 631 638.

94. Zernecke A. 2015. Dendritic cells in atherosclerosis: Evidence in mice and Humans. Arterioscler Thromb Vasc Biol, 35: 763 - 770. 